\title{
Chinese Classes Promote Language Use Strategy Research
}

\author{
Ai-Rong ZHANG \\ Journal of Weinan Vocational \& Technical College, China \\ Email:wnzykyc@163.com
}

Keywords: Chinese language teaching, practice course

\begin{abstract}
Chinese? The issue of Chinese has been discussed. Chinese teachers put a lot of time on the analysis and discussion of the text of the thoughts and feelings, the language on the edge of the large and empty, lost the true face. In this paper, the author believes that the language is to learn the language, learning the use of language integrated practice courses.

2001 edition of the compulsory education Chinese course standard $\backslash$ "that define the nature of the Chinese curriculum: $1 "$ the language is an important communication tool, is an important part of human culture. The unity of instrumental and humanism, is the basic characteristics of Chinese curriculum.।" The 2011 edition of the compulsory education Chinese course standard $\backslash$ "the nature of Chinese curriculum to defined: $\backslash "$ language is a language learning words using integrated and practical course. $\mid "$ Below my 20 years of teaching about my understanding of this sentence.
\end{abstract}

\section{First, the Language is Used to Learn the Language}

Since a long time, the Chinese have been discussing language lesson should teach? The problems in the curriculum standard of 2001 seemed to have the answer that is the language of humanity and instrumental. Result in such calls, our Chinese teaching will be main goal orientation on learning the text content, language lesson cost a lot of time to understand and comprehend the text of the emotional expression of thought. Speak language lesson is to read the text, from the text to ideological content, and the expression form of the article, artistic characteristics and so on. We think of it, these big and empty the humanity can really tell us what literature, the teacher teaches what problem? The time to tell we can't. And Chinese curriculum problem is more and more prominent, like reading and expression of imbalance, the teaching content of fragmentation, fragmentation and so on.

Until the 2011 edition of the compulsory education Chinese course standard ", "language is a language learning words using the integrated and practical course." We didn't found her natural language. Language is our culture, it is our root, as the Chinese do not study our national culture, how can you say in the past? Don't know since when, all of our children into all kinds of English training, the child's parents together to explore is how to improve children's English level, seem to learn English well, everything is Ok. But we have a lot of children words also say not clear, let alone write a composition. Especially in primary school and junior high school students, high school students, of course, is no exception, a file to write a composition is a headache. Ask why, all said there is no content, have no words to write; Or don't know how to write? Don't these we can reflect the language teacher seriously? Imagine if everyone took out to learn English harder to learn our language, learning our language and words, the consequences would be like? So now we must attach importance to language learning.

For many of our teacher, change our classroom, the authenticity of the real language back to her, this also is the present Chinese teaching urgently needs to solve the problem. For teachers, the most important thing is, from the perspective of the language, what synonyms comparison, different sentence patterns by comparing words accuracy, small practicing writing, etc., should let the students learn to learn knowledge, rather than spending many years children also learn can't analyze the text. Attaches great importance to the students using language skills and skills training. 


\section{Second, the Language is Used to Learn to Use Language.}

The ultimate goal of learning Chinese, or in order to apply, let language tools really become the student thought. Now many students love new vocabulary, or randomly on vocabulary, sentence omitted to add, make the person confused about, such as "difficult, don't hurt, I often go to, but there is no use", and so on, if you don't check online, didn't understand the meaning of these words. As a mandarin tester, in recent years the children said topic is lower and lower test scores, why? Or language use is not standard, the most basic of quantifiers are not used, what is "an arm and a leg, a hand" such a question often appear in talk, isn't that the use of the language problem? So on the basis of learning language, must learn to use, and is a specification to use. Really the language of the Chinese nation culture charm to the world.

2011 edition of the new standard, use frequency is highest is to use a word, must be left Chinese teaching in practice. What is language? In simple terms, language is speech; For the human society, language is thinking and a tool for communication, is the direct form of "thought" (Marx); In a sense, the language is the thought itself, is the content of the thought as well as in the form of thought. Text is a kind of language symbol system, resorting to visual symbol system, is the visual form of language. Created the human language and then created the text. Text broke through the spoken language is limited by space and time, can play a greater role. 2011 version of the "preface" Chinese course standard points out: "language is the most important human communication tool and information carrier, is an important part of human culture." Language is a nationality, hidden in the "language" is here for the definition of "language", points out the content of the language learning and the object is language and language use, is the han nationality's language and its use, is the mother tongue education. We communicate, thinking, records, expression and inheritance is inseparable from the language. "The same language is home" (heidegger), then, "language use" is a person to prove their existence in consciously and unconsciously a basic life activities.

Chinese subject is to guide students to better grasp and use the motherland language, national culture and national spirit foundation of service, "language use" undoubtedly reveal the characteristic of the language is the language of the most basic. Chinese teaching is to learn the use of language teaching, only in learning language use and good kung fu, Chinese language teaching to go on the right path.

As a language teacher, to always remember this, in every class practice this, word class, we can let students use words to talk, use multiple words the plait story. Reading teaching, we must constantly with the aid of teaching material of this example, let the students read the author's writing, timely for oral language and written language migration, more responsibility, writing teaching material to guide the student to study the accumulation, and the basic methods of organizing, to help students to better use the language of text, makes language really express students the tools of thought.

\section{Three, the Language is Used to Study Language Use Comprehensive Practical Course.}

Published in 1962, the people's education "by guo moruo about writing inscription:" training of primary and middle school students write good word, don't have to become a calligrapher, everyone always take care handwriting specifications, the more correct. Clean and easy to recognize. This habit is good, can make the person carefully, easy to focus the will, a good and considerate man. Hurry, careless, autocratic, is easy to spoil the broth. Practice writing can gradually to waive these problems." Review of twenty years of teaching experience, who makes his own business, or life good students, which is not beautiful handwriting, or regular? Knowledge, real knowledge comes from practice, Chinese teaching must attach importance to the practice of language, understand cultural connotations and language application in practice.

In addition, the language teacher should change concept, first of all to accept at Shanghai normal university professor Wu Zhonghao's point of view, from "teaching" the text to the change of "teaching language". If the conceptual change, that we Chinese will have very big difference. How to go, I think will back to the 2011 version of the curriculum standards, read read through the 
curriculum standard, the curriculum standard and build a bridge between the text and Chinese teaching can emit its charm.

\section{Reference}

[1] Marx, Engels. Marx Engels complete works [M]. third volume. People press, 1960:525

[2] Heidegger. Existence and time [M]. life, reading books, new knowledge, triple bookstore, Revised Edition 2006

[3] Yu Yongzheng. How can I teach Chinese [C]. Beijing: Education Science Press, 2014.1. 